\title{
El acueducto de Guadalajara y la obra de fray Pedro Antonio de Buzeta en España y Nueva España
}

\author{
por \\ Álvaro Recio Mir \\ Universidad de Sevilla y Universidad Autónoma de Chile \\ alvarorecio@us.es
}

El acueducto de Guadalajara, construido por fray Pedro Antonio de Buzeta entre 1731 y 1741, fue una de las principales obras virreinales de la capital tapatía. Sus antecedentes se remontan al siglo XVI y sus consecuencias se prolongaron hasta el siglo XIX. A partir de documentación inédita del Archivo General de Indias, hacemos un análisis de esta empresa constructiva y de la actividad de su autor, tanto en España como en América.

Palabras Clave: acueducto; Guadalajara; fray Pedro Antonio de Buzeta; siglo XVIII; fuentes; construcción.

El abastecimiento de agua a Guadalajara se gestó desde la fundación de la ciudad en el siglo XVI y se prolongó hasta el México independiente ${ }^{1}$. Tras varios proyectos frustrados, el definitivo lo activó la real cédula de 21 de noviembre de 1727 en la que Felipe V mandó iniciar las obras a la Audiencia de Guadalajara. Esta nombró en 1729 director de las mismas a su oidor don Juan Rodríguez de Albuerne, marqués de Altamira ${ }^{2}$.

\footnotetext{
${ }^{1}$ Un resumen de ello se hace en López Cotilla, 1842. También en Jalomo Aguirre, 2011: 154 y ss.

${ }^{2}$ Archivo General de Indias, Sevilla (AGI), Guadalajara 420, fols. 137-146. 
I. El proyecto de fray Pedro Antonio de Buzeta (1731-1732)

Albuerne fue quien eligió a fray Pedro Antonio de Buzeta, del que dijo que era «religioso lego de la observancia seráphica, conventual de la ciudad de Sanlúcar de Barrameda en esos reynos y limosnero de su convento en estos, maestro arquitecto y de cañerías, que en dicha ciudad de Sanlúcar había hecho la obra de conducir el agua de su convento y la aclamada de la ciudad y puerto de Nueva Veracruz en estos reynos».

Al saber Albuerne que estaba en la ciudad de México, escribió a su Audiencia para que «remitiesen a dicho religioso o al maestro que juzgasen de mayor satisfacción y confianza y se me respondió que ninguno más apto que el religioso» ${ }^{3}$.

Buzeta confirmó tales datos y especificó que, «habiendo pasado desde el real y minas de Pachuca a México» y luego a Guadalajara, entró en ésta el 8 de noviembre de 1731 para «dirigir la mencionada obra». De inmediato y acompañado por Matías de Ávila, «maestro carpintero y arquitecto», el franciscano hizo «la inspección y previos reconocimientos necesarios». En primer lugar, vio que

...el agua del río Tololotán, vulgarmente llamado el río Grande, necesita de muchos rodeos para conducirse a esta ciudad y sería preciso caminase como veinte leguas, en cuio espacio median algunos arroyos y otras quiebras de tierra que era menester salvarlas con arcos de mampostería y aunque pudiese venir la mayor parte de dichas veinte leguas sin tarxea y sólo por zanja de tierra era preciso la tarxea, a lo menos de cal y piedra, en quatro leguas para llegar a esta ciudad por su terreno de arena falso y deleznable, siendo también necesario construir presa en el río para la toma del agua con sus ladrones a fin de que no entrase en tiempo de avenidas demasiada porción que derrumbase la zanja y serían sumos los costes de uno y otro y no menores los que diez años después de efectuada la obra se necesitarían para reparos en ella ${ }^{4}$.

Es decir, el río Grande planteaba tres problemas: estaba lejos de Guadalajara; los desniveles del terreno habría que salvarlos con arquerías y debido a la inconsistencia del suelo el agua podría ser traída solo parcialmente mediante zanja -definida como «cortadura para que se escurran las aguas»- por lo que habría que construir cuatro leguas de atarjea o «caja de ladrillo con que se cubren las cañerías para su defensa». Esta propuesta también necesitaba

\footnotetext{
3 Ibidem, fols. $86-87$ vto.

4 Ibidem, fols. 153-155 vto. Sobre el entorno de Guadalajara véanse Arregui, 1980 y Mota Escobar, 1993.
} 
la construcción de una presa en el río, para que mediante «unos ladrones o portillos que se hacen en un río, acequia, etcétera, para sangrarlo», se pudiese conducir el agua sin problemas de avenidas a la zanja-tarjea. Todo ello hacía que esta solución fuese muy cara ${ }^{5}$.

Buzeta barajó otras posibilidades. Así, «del arroyo de esta ciudad queda dicha su poca altura y que ni pudo dársela antiguamente». Por su parte

...las aguas que ay en el oriente de esta ciudad, de la otra banda de dicho arroyo, así en tierra que oy posé don Joseph de Alzate, como en el rancho de don Antonio Fernández Chasco o en el arroyo del pueblo de San Andrés, las dos primeras carecen de altura competente y la última, que dista más de una legua de esta ciudad, nunca pudiera venir enderechura por el bajío tan grande que ay en el arroyo de ella, pues fuere preciso pasarla por muchos elevados arcos y con todo eso sería dificultoso proporcionarla al poniente de esta población que es lo más alto de ella, o se avía de traer dicha agua desde el oriente, atravesando el sur para el poniente e introducirla por este viento que es por donde está superior la ciudad y en este caso avría de andar el agua más de dos leguas con la dificultad del gran bajío que avía de atravesar el viento sur $^{6}$.

Buzeta presentaba así sus objeciones al arroyo de la ciudad y a las aguas de su oriente, las cuales unas tenían poca altura y otras necesitaban de arquerías en su tránsito. Por ello continuó su inspección del entorno de Guadalajara, apuntando que el río «que llaman Blanco y corre también al norte de esta ciudad se halla como a distancia de cinco leguas de la otra parte del de Zapopa y para traerlo enderechura era preciso pasase por encima de éste con muchos y muy elevados arcos que avían de cimentarse en terreno falso y deleznable y aunque quisiera traer el agua por los pueblos de Ocotán y Jocotán que están al poniente de esta ciudad sería preciso rodear más de tres leguas minando mucha parte en igual terreno arenisco siendo necesario para el agua de dicho río Blanco el que fuese conducido todo el camino por taxea de cal y piedra» ${ }^{7}$.

Debido a que las aguas al norte de la ciudad presentaban iguales problemas que las anteriores, Buzeta dictaminó «hayo no estar ninguna de ellas con las proporciones necesarias para la conducción a esta ciudad» ${ }^{8}$.

Tras ello describe Guadalajara y su entorno:

5 García Salinero, 1968: ad vocem. Sobre la terminología hidráulica véanse también Icaza Lomelí, 1985: 20-33; 1988: 221-251. González Tascón, 1992: vol. II: 679-714. Icaza Lomelí, 2009a: 6-36; 2009b: 192-215. Escamilla Bran, 2009: 123-141.

${ }^{6}$ AGI, Guadalajara 420, fols. 155 vto. y 156.

7 Ibidem, fols. 156 y 156 vto.

8 Ibidem, fol. 156 vto. 
...situada en un espacio llano, su figura es casi quadrangular, con declinación del poniente para el oriente y alguna también para el mediodía y norte, siendo mayor la caída del medio para el oriente, cuio costado lo ciñe extramuros un arroyo que naciendo a mediodía no mui distante endereza su curso al norte de ella y este costado y el de oriente son los más escasos de altura. Tampoco la tiene el de mediodía, por donde se avecina al oriente y sí por lo que se acerca al de poniente, siendo éste el que entre todos sobresale, coronado, a distancia como de tres leguas de la ciudad, de unos cerros que declinan a ella, no con poca proporción de altura en el llano que intermedia y a 2500 varas de la población supera en más de treinta rematando cerca de la ciudad con más de diez y siete de exceso, pero en lo alto de dicho llano es mayor el descenso que éste tiene al norte, donde rompieron la falsedad de la tierra los expresados manantiales que forman dicho río de Zapopa. Entre éste y la ciudad nacen otros que aunque también bajos, no son tanto como los antecedentes y todos parecen traer su curso subterráneo por el referido llano, ya provengan de los referidos cerros que están al poniente o de los que por el sur les confinan y a unos y otros parece dimanan también dos ojos de agua que prorrumpen extramuros al sur de esta ciudad, advirtiéndose juntamente en la parte que de ella está al poniente que sin embargo de ser el sitio más alto tienen casi todas las casas sus pozos en altura de doze varas con agua de buena calidad y abundante, siendo verosímil que ésta y la de dichos manantiales corra difundida por el referido 11 ano 9 .

Debido a la existencia de agua subterránea y a su animadversión a las arquerías el franciscano ideó «buscarla allí, bajo de tierra, como se está executando». Vio así que el agua se encontraba a una profundidad de doce varas, unos diez metros, superando «en más de treinta a la plaza maior de esta ciudad», por lo que lógicamente «sangrando el más bajo pozo de dicho llano excede todavía en altura de diez y siete varas a dicha plaza mayor y por consiguiente tiene el agua altura para repartirse a las fuentes públicas, real palacio, cárcel de corte, cabildo, casa episcopal, conventos y casas $\rangle^{10}$.

Buzeta planteó un proyecto que «comienza en dicho llano de poniente de esta ciudad y a distancia de ella como de dos mil y quinientas varas», unos dos kilómetros. Ochocientas varas a poniente se habrían de abrir «de cinquenta a cinquenta varas pozos, lumbreras o rexistros de más de seis de circunferencia para minar después de unos u otros todas las ochocientas o más varas a cuia mina concurran los veneros de agua que juntos se han de conducir a esta ciudad, sangrándolos con suficiente altura para ello en el paraje que pareciese más a propósito del resto de las mil y trescientas varas» ${ }^{11}$.

\footnotetext{
9 Ibidem, fols. 156 vto. y 157

${ }_{10}$ Idem.

11 Ibidem, fols. 157 y 157 vto.
} 
Es decir, el primer ramal del acueducto sería una mina o galería de ochocientas varas, ejecutada a partir de pozos abiertos cada cincuenta varas, que luego se unirían subterráneamente. A esta mina concurrirían los veneros del subsuelo del entorno de Guadalajara, que serían conducidos a la ciudad.

El arquitecto seguía describiendo el proyecto, a cuya línea de poniente se uniría otra de más de mil varas «de sur a norte, también con sus lumbreras o registros de zinquenta a zinquenta varas y comunicados después todos por mina en el plano que se hallase el agua, con cuia línea traviesa se cortarán muchos veneros derramados y dispersos por el llano y algunos o parte de los manantiales arriba expresados, que todos han de venir a juntarse en la otra línea que baja del poniente a esta ciudad ${ }^{12}$.

Planteados los dos ramales que confluirían en la ciudad, Buzeta señalaba que «en las minas de estas dos líneas se ha de formar una tarxea de siete quartas de alto y dos tercias de ancho, cubierta con losas grandes o cantería, de manera que pueda entrar un hombre siempre que se ofrezca por las lumbreras o registros, que para ello han de quedar de zinquenta a zinquenta varas y la dicha taxea a de ir vestida de cal y piedra por los costados, con pared de media vara de grueso a lo menos, pero el plan de ella ha de quedar desnudo para que salga el agua y reciba todos los sudaderos o manantiales que por qualquiera parte concurrieren a dichas dos líneas» ${ }^{13}$.

El proyecto era imponente, ya que la mina albergaría una atarjea por la que cabría un hombre, que accedería a ella por los pozos para solucionar futuros reparos.

Seguía nuestro autor indicando que el agua de ambos ramales iría a parar a un arca o tanque cerrado y se formará la tarxea de cal y piedra en el plan y lados con buen macizo para que no se desperdicie o salga alguna agua y así se ha de conducir hasta que llegue a la altura proporcionada para poder formar las fuentes necesarias y entonces se ha de hacer otra arca para el repartimiento de las cañerías que an de ser de caños bien gruesos y bien macizos ${ }^{14}$.

Es decir, el agua de las minas iría a parar a un arca, caja o almacén de agua, de la que saldría por una atarjea que la llevaría a las fuentes. Alude Buzeta también a una segunda arca de distribución.

Consciente de las dudas que planteaba el abastecimiento subterráneo, su autor lo fundamentó indicando que «es el más seguro y permanente y no será necesario en muchos siglos reparar la taxea ni menos puede dudarse la abundancia y seguridad del agua por que esta se ha encontrado en los primeros

\footnotetext{
12 Ibidem, fol. 157 vto.

${ }_{13}$ Idem.

14 Ibidem, fols. 157 vto. y 158.
} 
pozos de la línea que sube de esta ciudad para el poniente a doce varas de profundidad y con tanta abundancia que no es posible profundizar otras dos varas por la mucha agua que arrojan ${ }^{15}$.

Buzeta dijo que la obra costaría sesenta mil pesos, más sus honorarios, «dos mil y quinientos pesos en cada un año, lo mismo que gocé en Vera Cruz por despacho del virrey marqués de Valero, que remito testimoniado y aún aseguro que la ciudad me pagó a razón de tres mil pesos».

Sobre el plazo de ejecución aclaraba que los «meses de junio, julio, agosto, septiembre y octubre son aquí continuos y copiosos los aguaceros y así en estos meses con dificultad se podrá trabajar, mayormente en un terreno de arena, falso, deleznable, expuesto a derrumbes y ruinas». Por ello, calculó un plazo de dos años y medio. Todo lo anterior lo firmó en Guadalajara el 1 de febrero de $1732^{16}$.

Otras declaraciones suyas inciden en la explicación del proyecto. Así, señala que habría agua para cinco fuentes, «quanta quisieren para sus casas los vecinos, también para obraxes, para batán y para molino harinero, para las catorce comunidades que ay en esta ciudad, para el real palacio, reales cárceles, catedral, casa del señor obispo y las de vecinos particulares» ${ }^{17}$.

El franciscano además aseguraba que el agua sería de calidad y «que aquellos que tanto hasta ahora han hablado contra la obra, no podrán dexar de confesarla no sólo fuerte, segura y sin alguno de aquellos imposibles que avían ponderando, voceando y hecho creer a todos, sino también insigne y magnífica», ya que también se podrían «hacer huertas y otras muchas cosas que produzcan considerables fondos» ${ }^{18}$.

Buzeta incluía un borrador, croquis o apunte sobre su proyecto. En él se suceden los tachones, sus leyendas están en distintos sentidos y hay varios tipos de letras y $\operatorname{tintas}^{19}$. En cualquier caso, es fuente esencial sobre la ciudad y su acueducto.

Al Norte está «el río Blanco» y los «Ojos del agua del río Izapopán». Junto a ello una inscripción dice «una legua y media de Guadalaxara a este río»; otra indica «rancho de Ysidro Enríquez», al lado del cual hay un ojo y un delgado curso de agua. En el Este está el «río Grande», que rodea la ciudad. Del mismo se dice que es cruzado por «Totolotlán puente» y que hay «5 leguas de Guadalaxara a este río». Afluente del Grande es el «río de Guadalaxara».

15 Ibidem, fols. 158 y 158 vto.

16 Ibidem, fols. 88 y 158 vto.- 160 .

17 Ibidem, fol. 245 vto.

18 Ibidem, fol. 246.

19 AGI, Mapas y planos, México, 127. 
EL ACUEDUCTO DE GUADALAJARA Y LA OBRA DE FRAY PEDRO ANTONIO DE BUZETA EN ESPAÑA... 723

Figura 1. Proyecto de acueducto para Guadalajara

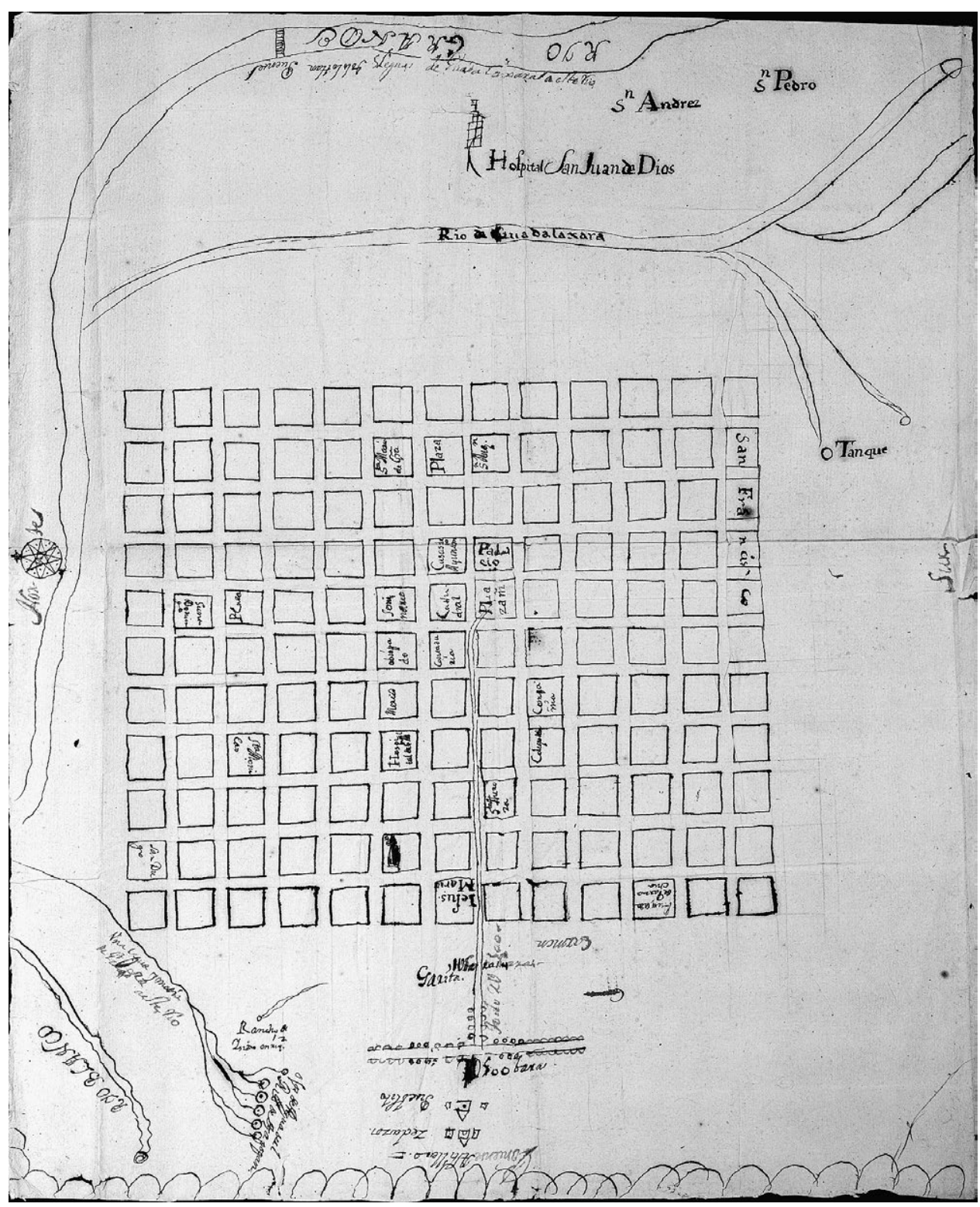

Obra de fray Pedro Antonio de Buzeta, 1732, Archivo General de Indias, Mapas y planos, México, 127. 
Figura 2. Detalle del Proyecto de acueducto para Guadalajara

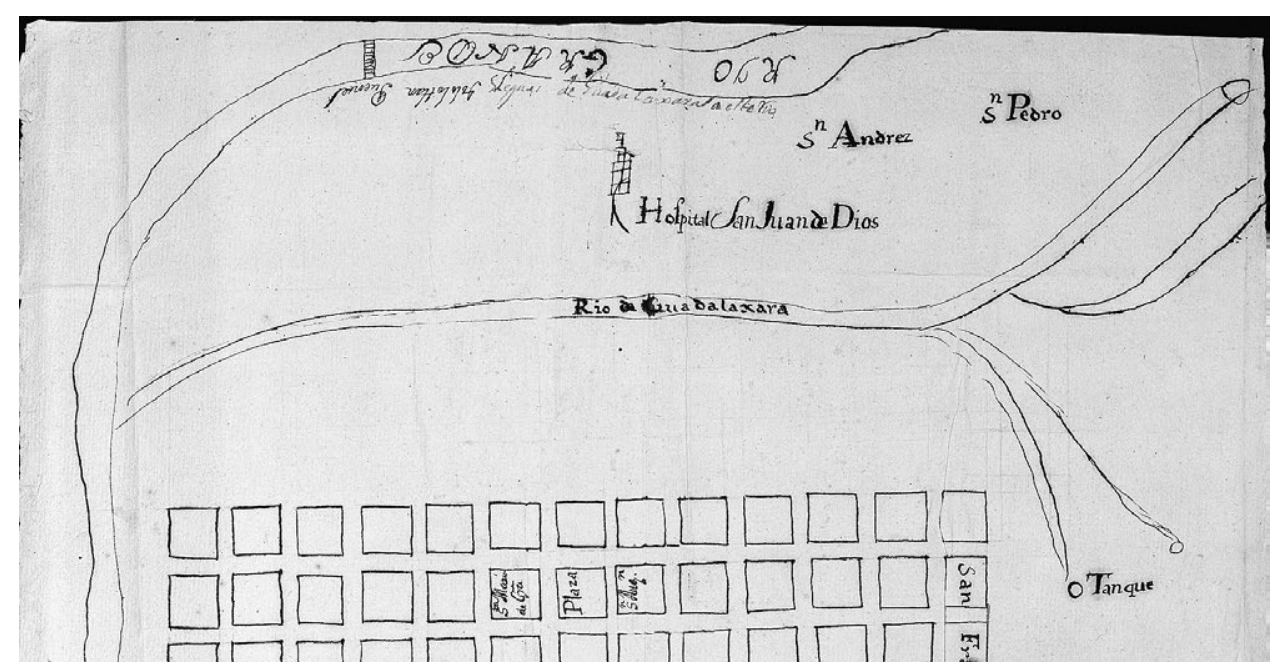

Obra de fray Pedro Antonio de Buzeta, 1732, Archivo General de Indias, Mapas y planos, México, 127.

Entre ambos está el «hospital de San Juan de Dios» y los pueblos de «San Andrés» y «San Pedro». Al Sur hay un «tanque» junto a un ojo de agua que muere en el río de Guadalajara. A «poniente» leemos «astillero», «zedazos»y «pueblito». En otro sentido y con otras tintas vemos «3.500 baras», «garita», «1.000 baras», «todo 2.500»y «Carmen».

Figura 3. Detalle del Proyecto de acueducto para Guadalajara

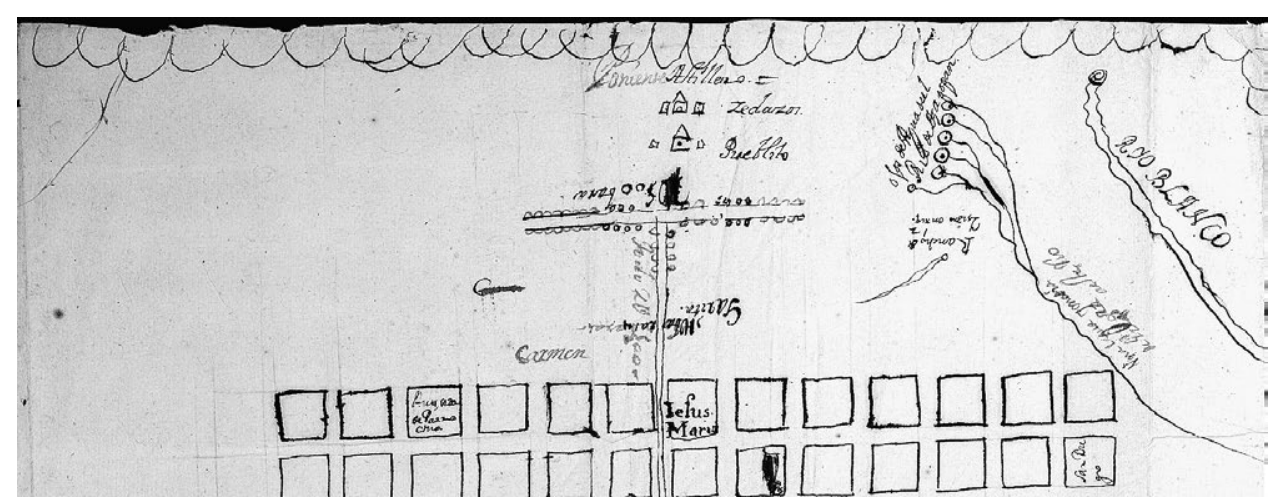

Obra de fray Pedro Antonio de Buzeta, 1732, Archivo General de Indias, Mapas y planos, México, 127. 
En la ciudad vemos sus principales edificios en torno a la «plaza mayor»: «palacio», «casas de ayuntamiento», «catedral», «contaduría», «seminario», «obispado», « Merced » y «hospital de la Merced». Al Norte «Santo Domingo», «Santa Mónica», «San Diego» y una «plaza». Al Este «Santa María de Gracia», «San Agustín» y otra «plaza». Al Sur «colegio de la Compañía» y «San Francisco» y hacia «poniente», «Santa Thereza», «Jesús María» y una «ayuda de parroquia».

Todo indica que los «Ojos del agua del río Izapopán» eran el ramal de poniente del acueducto, mientras el tanque del Sur, estaría en relación con el ramal Sur-Norte. Ambos ramales se unirían a poniente, entrando en la ciudad por la garita referida en la documentación y el croquis. Por lo que se refiere al interior de la ciudad, el mapa parece indicar que el agua entraría desde el convento de Jesús María a la plaza mayor.

Cabe preguntarse por la causa de que un mero esbozo formase parte del expediente enviado a España para ser juzgado. Buzeta tenía mayores cualidades expresivas, por lo que es posible que el verdadero proyecto quedara en Guadalajara para su ejecución. Sea como fuere, las ideas del franciscano -aquí rudimentariamente planteadas- no siempre coinciden con el texto del proyecto, donde planteaba dos cajas de agua, aludiendo aquí a sólo un «tanque». En cualquier caso, este mapa de 1732 es la más antigua planta de Guadalajara y de ella fue autor fray Pedro Antonio de Buzeta ${ }^{20}$.

\section{LA CONSTRUCCIÓN DEL ACUEDUCTO (1731-1741)}

De la obra del acueducto de Guadalajara, que duró una década, contamos con numerosos informes y datos que permiten trazar con precisión su evolución.

\section{II.A. Informe de 2 de enero de 1732: inspección del terreno e inicio de la obra}

El primer informe lo redactó el superintendente Albuerne, que indica que Buzeta reconoció los ríos, arroyos y manantiales de los contornos de Guadalajara y en ninguno encontró agua suficiente, por lo que la buscó en el subsuelo, «en un llano que por espacio de tres leguas desciende a esta población con proporcionada altura de unos cerros distantes de la ciudad 2.500 varas

${ }^{20}$ Ni la bibliografía recoge esta autoría, Calderón Quijano, 1984: 62 y 63; ni la ficha del plano en el AGI, Mapas y planos, México, 127. 
en línea recta desde el centro de la población y de 30 varas de altura. A las 12 o 13 varas se encontró el agua» ${ }^{21}$.

El informe añade que la obra se inició el 19 de noviembre de 1731, de forma que en enero, cuando se fecha el informe, sólo se habían abierto 2500 «varas que forman dichas dos líneas, con paredes de siete quartas en algo por los costados de piedra, dos tercia de hueco y cubierta la taxea con las losas o cantería quedando el plan desnudo para recibir los veneros sangrándolos después en el descenso del llano de la ciudad con altura proporcionada al repartimiento de las fuentes que es el modo mismo con que el religioso condujo el agua a la ciudad y puerto de Nueva Veracruz en estos reinos y a su convento de Sanlúcar en esos» ${ }^{22}$.

El informe añade que se comenzó la obra por una zanja, «pero viendo su desmedido coste en sacar de tanta profundidad la tierra y que la arena era más sólida y tupida, se logró para la maior parte el arbitrio de mina, asegurada con pozos o lumbreras de 50 a 50 varas que después servirán para administrar los materiales de la taxea quedando para registros» ${ }^{23}$.

\section{II.B. Informe de 5 de septiembre de 1732: técnicas y materiales}

Albuerne, en septiembre de 1732, encargó al escribano Manuel de la Sierra que reconociese la obra. Este segundo informe señala de la misma que, iniciada hacía nueve meses, se ubicaba

...en un llano que baja de unos zerros al poniente de esta ciudad, siendo el ánimo de dicho religioso aí por lo que es público como por lo que demuestra lo ya obrado cortar en dicho llano los veneros de agua subterránea para conducir a esta ciudad, a cuyo fin por dicho poniente como a ochocientas varas de esta población se abrió una sanja que comenzó en cuatro varas de profundidad y subiendo para el poniente en línea recta fue bajando proporcionadamente hasta la profundidad de más de dos varas, en cuya sanja se ha ido construyendo tarjea de cal y piedra con simiento de media vara de grueso y sobre él paredes por los costales del mismo grueso cada una de ellas y de vara y media de alto y dos tercias de güeco de una a otra pared, cubiertas estas con losas de a vara y sobre el simiento de la targea solado todo de ladrillo y revocado por encima de cal y sobre las losas que sierran la targea terraplenada la sanja hasta la superficie del llano en cuya conformidad se hayan concluidas y acabadas como ochocientas varas de targea que aunque no la he medido parece serán poco más o $\operatorname{menos}^{24}$.

${ }^{21}$ AGI, Guadalajara 420, fols. 86 vto. y 87.

${ }^{22}$ Ibidem, fols. 87 y 87 vto.

${ }^{23}$ Ibidem, fol. 87 vto.

${ }^{24}$ Ibidem, fols. 192 y 192 vto. 
Tras explicar cómo se estaba construyendo la atarjea, añade que también se habían construido los pozos de acceso a la misma, a los que se alude como

...catorce registros que sobresalen más altos una vara que la superficie del llano, hechos de cal y piedra y con el hueco de una vara por donde pueda bajar un hombre a dicha targea y andarla por dentro toda, cuyos registros están a distancia unos de los otros de más de sinquenta varas y el simiento de dicha targea por la parte que mira a esta ciudad está como tres varas y media más bajo que la superficie del llano por averse comensado como dicho es en profundidad de quatro varas y llevar el sumidero media vara de grueso como queda expresado, pero en el extremo de la línea al poniente se halla ya el simiento de dicha targea como en dose varas de profundidad y por este extremo (siguiendo línea recta a la targea ya serrada y concluida) se hallan como otras siete baras más de simiento, parte con paredes y parte sin ellas, a que sigue continuando dicha línea a poniente como otras sien varas minadas sin simiento alguno que me aseguró el religioso se minaban sobre el agua y más arriba por donde va siguiendo la mina ay abiertos y se están abriendo diferentes posos y por el extremo que baja a esta ciudad (consiguiente a la línea de dicha targea concluida) se hallan abiertas otras más de sien varas de sanja ${ }^{25}$.

El informe también hace alusión al abasto de los materiales, especificando de la Sierra al respecto, en la referida fecha de septiembre de 1732, «doi fe que aviéndose pregonado ante mí y en virtud de auto de dicho señor oidor superintendente por espacio de treinta días quando se comenzó dicha obra para si alguna persona quería hacer postura a ella o a los materiales de cal y piedra, manifactura de la tarjea y cargo de abrir las sanjas o minas, no hubo postor alguno sino sólo para la cal, a la que hizo postura don Juan de Urquiza, ofreciendo dar a sinco reales carga según consta en los dichos pregones a que me remito» ${ }^{26}$.

Nos informa así de que, aceptado el proyecto de Buzeta, su ejecución fue ofrecida a pregón, pero al no haber ofertas, fue el franciscano quién la acometió. También se sacó a subasta el acopio de materiales, de los que sólo se consiguió por tal sistema la cal.

\section{II.C. Informe de 4 de enero de 1733: primeros resultados}

En el tercer informe Buzeta anuncia a Albuerne que había llegado el tiempo «de ensanchar el pecho y desahogar el corazón» frente a las «porfiadas tormentas que la ignorancia, la necedad y la envidia levantaron contra» el acueducto.

\footnotetext{
${ }^{25}$ Ibidem, fols. 192 vto. y 193.

${ }^{26}$ Ibidem, fol. 193 vto.
} 
El franciscano añade que «sólo se han minado 160 varas de la cortadura» y ya había agua suficiente para cinco fuentes. Teniendo en cuenta que «dicha cortadura puede extenderse hasta más de nueve mil varas por tener cerca de dos leguas de latitud, ya no podrán negar que se contará no sólo con el agua suficiente para el púbico y quanta quisieren para sus casas los vecinos, sino también para obrajes, batán y molino harinero dentro de la ciudad».

Tampoco se podría ya dudar de la altura del agua, «pues han visto correr dicha agua por la superficie superior a lo más alto de esta población». A ello sumaba «la excelentísima calidad del agua», de forma que muchos «envían por ella a la obra $\rangle^{27}$.

Buzeta, que se reafirmaba en su propuesta de abasto subterráneo, no deja de señalar las contingencias producidas: «muchos derrumbes que han padecido las sanjas y las segundas en los cavellos o betas de tierra que extravían los veneros y de que ha sido presiso huir con indispensables y maiores gastos».

Además, el 17 de abril de 1734 abandonó la obra al no haber cobrado. Albuerne le pidió que volviese, lo que sólo consiguió en abril de 1737. Así, concluyó la mina el 22 de marzo de 1738, tras lo cual la actividad se centró en la atarjea de cal y canto, que incluía caños de barro ${ }^{28}$.

\section{II.D. Informe de 19 de noviembre de 1738: primera medición de agua}

En el cuarto informe, de 19 de noviembre de 1738, Buzeta dice que estaba «fenecida toda la tagea hasta la caxa de donde ha de salir la cañería para esta ciudad y está dicha caxa a quinientas varas de la población con altura bastante para que el agua suba a las fuentes públicas» ${ }^{29}$.

Era un momento culminante, ya que el 16 de noviembre se había medido el agua «recogida que viene por la expresada tagea y sale a la referida caxa» y se halló «siento veinte y dos pajas de agua que por dicha tagea vienen a la referida caxa». Además de la cantidad de agua, 122 pajas, y de que la obra se había convertido en un espectáculo, especificaba Buzeta que el abasto no era regular, ya que en la temporada seca «se disminuía una tercia parte» ${ }^{30}$.

En cualquier caso, el agua era suficiente para nueve fuentes públicas que

27 Este informe es recogido en Ramos, 1942: 218-226.

${ }^{28}$ López Cotilla, 1942: 7. Jalomo Aguirre, 2011: 157.

29 AGI, Guadalajara 420, fols. 286 y 286 vto.

30 Ibidem, fols. 286 vto.-287. Cada paja eran unos dos centímetros cúbicos de agua por segundo. Véanse González Tascón, 1992, vol. I: 189-194 y Terán Trillo, 2009: 45 y 46. 
...yo premeditaba distribuir en esta forma: tres en las plazuelas del mesón que llaman de Fernando, convento de Jesús María y ayuda de parroquia, que están en igual paralelo de norte a sur por donde ha de entrar el agua y con que se abastece todo el vecindario del poniente de esta ciudad; otras tres fuentes en la plazuela de Santo Domingo, plaza Mayor y plazuela de San Francisco, que así mismo están en igual proporción de norte a sur y como la de la plaza Mayor necesita ser la más copiosa de todas, con el remanente de ella, se pueden hacer otras tres fuentes, una en la real cárcel de corte y otra en el real palacio que se hayan en la misma plaza y en su frontis de oriente y la tercera de dichas fuentes en la plazuela que media entre los conventos de Santa María de Gracia y de San Agustín y en un mismo rumbo desde dicha plaza Mayor para el oriente, con cuyas nueve fuentes y especialmente con las siete públicas de la plaza mayor y de las plazuelas expresadas queda más que suficiente y cómodamente abastecido todo el vesindario, no sólo en su centro si no también en sus arrabales ${ }^{31}$.

El arquitecto franciscano «también jusgaba conveniente que antes de llegar el agua a la población se hiziese extramuros una pila bien prorrogada donde pudiesen beber los ganados que pastan en dicho llano del poniente y que del reciduo de dicha pila se formase otra para el uso de lavar respecto de hallarse aquella parte del vesindario a mayor distancia del riachuelo que por el oriente corre extramuros de esta capital» ${ }^{32}$.

La ambición de Buzeta pretendía hacer de Guadalajara una Roma tapatía con fuentes en sus principales plazas y edificios. Para ello alude al último elemento del acueducto que restaba por ejecutar: la cañería que llevaría el agua desde la caja a la ciudad, para la cual «es presiso prevenir antes quatro o sinco mil caños». Planteaba su suministro por los indios de Tonalán y San Pedro, a peso la decena,

...pero es necesario irles adelantando para ello el dinero como sucede en todos los
demás materiales y es imponderable lo que se padece para conseguir el cumplimien-
to, he experimentado en todos los siete años de esta obra, cuya delación pudiera
remediarse trayendo los oficiales cañeros a esta ciudad, armándoles hornos, condu-
ciéndoles la tierra y leña y rebajándoselo de dicho precio, pues con esto a menor
diligencia se lograría más prompto efecto. Necesitase asimismo alguna prevención
de cal, piedra y losas de cantería que llaman de Guentitán y todo se conseguirá
más cómodamente en la presente temporada seca hasta el mes de junio del año
próximo venidero por cuyo tiempo empiezan aquí los aguaceros y duran hasta
mediados de octubre por lo que desde entonces se podrán comenzar las cañerías ${ }^{33}$.

\footnotetext{
31 AGI, Guadalajara 420, fols. 287-288.

${ }^{32}$ Ibidem, fol. 288.

33 Ibidem, fols. 288 y 288 vto.
} 


\section{II.E. Informe de 18 de agosto de 1739: más agua}

Un nuevo informe de Buzeta, de 18 de agosto de 1739, alude a la cantidad de agua. Si en la medición de noviembre de 1738 el resultado había sido de 122 pajas, en la de 17 de mayo de 1739 «que han pasado seis meses de temporada seca se hallan dos pajas más y el motivo de no hallar más cantidad por noviembre fue por estar aterrada la tarjea del caracol con seis quartas de tierra y no haver llegado toda el agua y por estar acabada de hacer y los materiales secos».

En consecuencia, esperaba para la temporada seca próxima «ciento y treinta y seis pajas por lo que discurro se puede hacer más de diez fuentes con altura para lo más alto de la ciudad». No obstante, el franciscano confesaba dos razones «para no poner las otras fuentes que se siguen después de la fuente de la plaza», la primera era la falta de liquidez y «la otra razón es por hallarse el comercio atrasado y no alcanzarles este año la renta según es notorio que bien conozco precisa su consecución al palacio, cárcel y a las plazuelas de mis padres Santo Domingo y San Francisco» ${ }^{34}$.

\section{II.F. Informe de 17 de agosto de 1741: finalización y conservación del acueducto}

Junto a un informe de Buzeta de 17 de agosto de 1741, contamos con otras referencias de entonces, como la de «un testigo» que apuntó que la cañería de la conducción de agua «viene enterrada en dos varas de hondo para que no padesca con el tráfico de forlones y carretas, encaminada por dos cañerías, por si resiviere alguna contingencia de reventar el agua no falte esta al público mientras se compone».

A ello se añadía que la cañería contaba «con una vara de simiento de cal y piedra que la resive y media cara de pared por los lados del mismo modo que la defiende masisada en medio carcajo menudo y lechada y tapada con losas de piedra de sillería» ${ }^{35}$.

En cualquier caso, Buzeta planteó el 17 de agosto de 1741 que «una de las providencias más necesarias para la conservación de las cañerías y fuentes es nombrar maestro inteligente para que las cuide y avise de qualquiera quiebra que ubiese y la remedie».

Reconocía que el más apropiado era Sebastián Guerrero, «por haverlo traido siempre desde que empecé la obra y dado el gobierno de ella quando

${ }^{34}$ Ibidem, fols. 299 vto. y 300 .
35 Ibidem, fol 355

Revista de Indias, 2016, vol. LXXVI, n. ${ }^{\circ} 268,717-749$, ISSN: 0034-8341 doi:10.3989/revindias.2016.022 
por algún accidente no estaba yo presente». Especificaba que «le tengo enseñado el modo de nivelar el simiento para poner la cañería» y que «le enseñé a encañar ya que puso todos los caños de dicha cañería de su mano y a mi satisfacción en que no se ha reconocido defecto en lo que puso a su cargo». Añadía el franciscano que el referido Guerrero «sabe cómo está esta obra pues asistió en ella desde la primera piedra». También declaraba que «sabía armar qualquier fuente e introducir en ella el agua» y que era "capás para hacer otras cañerías y fuentes guardando las reglas que le tengo enseñadas». Por ello «es necesario a lo menos señalarle doscientos pesos en cada un año, los que se le pueden dar por tercios y será de su obligación mantener caballo para registrar toda la obra» ${ }^{36}$.

Buzeta incidía en el cuidado que habría de tener su sucesor, «en particular en tiempos de aguas por los arroyos de llovedizas que vienen por ensima los subientes no hagan algún daño». De igual forma, especificaba que las cañerías se habrían de limpiar cada quince días o un mes. La pila de la plaza se limpiaría en día de fiesta o por la tarde, «para que no haga falta el agua al común». Para los demás reparos a su sucesor «se le debe dar lo necesario para ello y pagarle los días que trabajase su jornal». Por si ello no fuere suficiente, el franciscano se comprometía a «dejar instrucción de todo lo que pude ofrecerle en dicha obra». También especificaba que, tras Guerrero, «el oficial que más conocimiento tiene de la obra es Baltasar de los Reyes» ${ }^{37}$.

Tras Buzeta, Guerrero fue nombrado «maestro de fontanero maior» el 26 de septiembre de 1741, y luego de los Reyes, «quien para los fines expresados se alla suficiente», fue nombrado «maestro de fontanero mayor», con un sueldo de 150 pesos anuales. Sus funciones eran «tener a su cargo las llaves de las caxas de agua, recorrer frecuentemente todo el camino de la cañería para reconocer si ay daños o quiebras y dar aviso de ellas a su señoría para el prompto reparo, sin que aya de llevar por ello más salario ni emolumento que el de los siento y sinquenta pesos y que no se haya de poder ausentar sin lisensia, así mismo ha de cuidad que cada quinde días se limpien las pilas de las fuentes públicas $\rangle^{38}$.

Fue el sucesor de Albuerne en la superintendencia de la obra, Francisco de Aysa, presidente de la Audiencia y marqués del castillo de Aysa ${ }^{39}$, quien informó al rey por carta de 16 de septiembre de 1741 de la llegada del agua

\footnotetext{
36 Ibidem, fols. 358-359.

37 Ibidem, fol. 359 vto.

38 Ibidem, fols. 428 vto., 361 y 361 vto.

39 Véase sobre él López, 1988: 181-185.
} 
a la plaza Mayor, plaza de las Carmelitas, palacio Real, cárcel, plaza de San Agustín y convento de San Francisco ${ }^{40}$.

\section{II.G. Informe de 7 de septiembre de 1741: gastos de personal y materiales}

La documentación de la obra recoge su contabilidad por semanas y en dos grandes partidas, personal y materiales, de lo que se ocupa un informe de Buzeta de 7 septiembre de 1741. En cuanto al personal, destaca su número, como muestra un apunte que alude a «nueve albañiles y siento noventa peones». También resulta interesante que se recojan nombres propios, como un pago «a Juan Marín, a quenta de las piedras que ha labrado de las pilas, subientes, escalones y losas» u otro «a Juan Agustín por los letreros y armas». Un ejemplo significativo es «por sien pesos que le di al maestro Sebastián Guerrero que le ofrecí al principio de la obra porque encañase con cuidado». Sin especificar su nombre se recoge otro pago «al campanero a quenta de las tasas», en relación a las de las fuentes y «por el mundo que está sobre las tasas de bronce». Buzeta también recoge «por nueve meses y ocho días de mi trabajo que ocupé en la limpia de la tarxea, serrar los posos y hacer la caxa principal del agua» ${ }^{41}$.

El capítulo de los materiales es especialmente prolijo, así, por citar sólo algunos apuntes, se dice: «por noventa y seis carretadas de piedra a quatro reales y vente carretadas de losas a diez reales»; «por ocho piedras para la pila de Santa Teresa»; «por palos para los andamios y para atajar las calles»; «por arena para mesclar y sacar tierra de la plaza»; «por seis arrobas de manteca para zulaque» o «por dos arrobas de plomo a dos pesos». En cuanto a las herramientas, se registran pagos por «seis asadones», «tres barrenas para barrenar la colina» o bisagras ${ }^{42}$.

En relación al abrevadero se pagó por «seis escalones para la pila», «por quatro piedras para las pilas que vevían las bestias», «por un mascarón y cinco pilares», «por diez carretas de piedra para empedrar alrededor de la pila». Otro ejemplo es el pago «por una pila para la real cárcel». Expresivos resultan los pagos de la fuente de la plaza Mayor, la más monumental: «por la hechura de mi padre San Francisco», «por los caños de bronce» o «por una cruz, dos pirámides y un mascarón» ${ }^{43}$.

\footnotetext{
40 Jalomo Aguirre, 2011: 157.

${ }^{41}$ AGI, Guadalajara 420, fols. 341-348.

${ }^{42}$ Ibidem, fols. 342-345 vto.

${ }^{43}$ Ibidem, fols. 345 vto.-347 vto.
} 
Este informe también ofrece descripciones de ciertos elementos de la obra:

...de orden verbal de vuestra señoría se le añadió para hermosear un subiente en las gradas de la catedral de cantería con las armas reales y tres inscripciones en sus tres frentes y ocho pirámides, remates y mi padre San Antonio, el protector de la obra, ensima de la pila de la plaza, con dos tasas de bronce y quatro pilas pequeñas en los quatro ángulos de la principal para que cómodamente veban las bestias de los que en los días de mercado acudan a ellas con sus defensas o resguardo para que las carretas no puedan ofender la dicha pila ${ }^{44}$.

\section{H. Informe de 16 de septiembre de 1741: descripción del acueducto}

El último informe, de Aysa, es de 16 de septiembre de 1741 e indica que, por falta de fondos, se solicitó dinero a diversos conventos «al rédito del 5 por ciento». Pero lo más interesante es la detallada descripción que hace del acueducto, empezando por un «lavadero de ropa y un aguaje para ganado donde por mejor suelo es continuo paraje de los arrieros de toda la tierra adentro», lo que les permitía «ahorrar una legua para dar agua a sus mulas». Asimismo, alude a «una pila pública en la pequeña plazuela que forma el convento de religiosas carmelitas por más proporcionado repartimiento». En cuanto a la plaza Real o Mayor, su fuente se levantó en el centro de la misma hermoseándola «y en un subiente que se construyó en la esquina que forman las gradas de la catedral se colocó una estatua de San Antonio», así como «las reales armas de vuestra majestad con las correspondientes inscripciones». Continúa indicando que, acabado «el dinero y necesitado a dar corriente al remanente de dicha pila, a continuos clamores de los presos de la real cárcel que vivían tan necesitados de ella», ya que «la que conseguían era de un pozo salobre y no alcanzaba a dar la necesaria, haciéndolo yo para la obra la mandé conducir dexando en el real palacio o suelo de él una pila con disposición de que sea verificada su fábrica y siguiendo la obra se conduxo dicha agua a la plaza que intermedia entre los conventos de San Agustín y religiosas dominicas de Santa María de las Mercedes».

También dice que «por el mismo arbitrio logré conducirla a la plazuela pública del convento de San Francisco» ${ }^{45}$.

\footnotetext{
${ }^{44}$ Idem.

45 Ibidem, fols. 278 vto.-279 vto.
} 
A la postre, la obra contó con un lavadero, una pila para ganado, una fuente en la plaza de las carmelitas, otra en la plaza Mayor, una pila en el palacio Real y la conducción a los conventos de San Agustín, las Mercedes y a la plaza de San Francisco.

Continúa el informe señalando que tras la plaza de San Francisco, se llevó el agua a la de Santo Domingo:

...prefiriendo dichos parajes no sólo por la proporción del arbitrio si no por ser los más necesitados, pues por la mala calidad de sus pozos no usan de ellos al paso que por lo contrario si los vecinos de la parte de poniente, como se manifiesta en el mapa de dicha real obra que se alla así mismo en los autos y en que van figuradas las pilas públicas y particulares construidas e iniciadas, las que con el tiempo combendrá hacer en el estado presente de la población de esta ciudad que va teniendo su aumento por dicha parte de poniente y en que se alla la real caxa del agua y los subientes quedaron prevenidos de caños para los aumentos de cañerías convenga hazer ${ }^{46}$.

La precaución del referido superintendente se evidencia en que, para los futuros reparos de la obra y debido a la falta de fondos para ello por «la falta de flotas», suplicaba al rey «la prórroga de los arbitrios para que pagado el comercio los cobren los oficiales reales y se pongan en la real caxa llevando quenta y razón de ellos para que siendo del agrado de vuestra majestad, se continúe la solicitud de más agua» ${ }^{47}$.

Con ello concluyó el acueducto de Guadalajara tras una década de obras. Pero junto a los informes hasta ahora recogidos, contamos con otras fuentes, como una descripción, suponemos que de la fuente de la plaza Mayor, que indica que tenía «cuatro ángulos y columnas en medio», a lo que se sumaban «dos tazas de bronce de mayor a menor, un globo encima de la taza principal y cuatro saltaderitos en forma de cruz» ${ }^{48}$. Por su parte, la Historia del reino de Nueva Galicia de Matías de la Mota Padilla, publicada en 1742, aporta un importante dato técnico, que «por ser el suelo de jale (piedra pómez) y arena deleznable» cimentó Buzeta «el conducto de hormigón de piedra y cal y embovedó una atargea capaz de que dos hombres anduvieran por ella con tal desembarazo, dejando a distancia lumbreras para su registro y volver a cerrar el tajo, quedando como antes en superficie y bien nivelado el conducto» ${ }^{49}$.

\footnotetext{
46 Ibidem, fols. 279 vto. y 280

${ }^{47}$ Ibidem, fols. 281 y 281 vto.

${ }^{48}$ Reynoso, 1967: 26.

49 Mota Padilla, 1973: 455.
} 
Ello da idea de la envergadura de la empresa y de que su autor estuvo atento a evitar lo que hoy técnicamente llamamos impacto ambiental.

A ello añade de la Mota Padilla ciertos detalles, como que el día de San Antonio de 1740 por primera vez corrió agua por la fuente de la plaza Mayor, que califica como «una de las más primorosas de Nueva España». Alude a otras fuentes en la plaza de las monjas de Santa María de Gracia, en la plazuela de Jesús María, en la de Santa Teresa, en la de San Francisco y en la de Santo Domingo. Además, señala las mercedes de aguas recibidas por el canónigo Eusebio Antonio de Riaza, don José de Segura y el convento de Santa Teresa entre otras. Para concluir, además de numerosos elogios de la obra, indicó: «yo atribuyo el feliz éxito de obra tan singular a la protección de San Antonio de Padua, a quien dicho maestro (Buzeta), encomendó sus aciertos» ${ }^{50}$.

También encomiástica fue la cita al acueducto de Villaseñor y Sánchez en 1745: «primorosa conducción y cañerías que se fabricaron a toda costa». Añade que Buzeta «calculó que los manantiales procedentes del cerro del Collí, hacia el poniente de la ciudad, tendrían un nivel superior a ésta y practicando tres (sic) series prolongadas de pozos, que convergieran a un centro, comunicándolos por cañones, logrando feliz resultado, habiendo brotado el agua de la fuente de la plaza mayor el 13 de junio de 1740. La obra se inició el 19 de noviembre de 1731 y aunque se suspendió por tres años se prosiguió sacando un costo de 75.269 pesos» ${ }^{51}$.

Junto a su autor, la gloria del acueducto de Guadalajara la compartieron sus superintendentes. Sobre ello señaló Villaseñor y Sánchez en 1748 que fue «el señor marqués de Altamira, licenciado don Juan Rodríguez de Albuerne, siendo oidor de aquella audiencia, quien la dejó en casa partidora, desde donde salen las tomas generales para la ciudad; siguiola en la construcción de sus fuentes y particiones particulares el señor marqués del Castillo de Aysa, presidente de la ciudad, y la feneció el señor don Martín Blancas, oidor de aquella Audiencia» ${ }^{52}$.

En cualquier caso, de la obra del franciscano nada queda. Sólo una ardua labor arqueológica permitiría su reconstrucción aunque fuese parcial de la que, sin duda, fue una de las más importantes empresas virreinales de la ciudad,

50 Ibidem: 456 y 457. Otro elogio de Buzeta lo hizo el doctor Lucas de las Casas en un raro impreso de 1742, citado en Cornejo Franco, 1993: XVI.

${ }^{51}$ Iguiniz, 1950, vol. I: 85 y 86.

52 Cornejo Franco, 1993: 140. 
la cual, pese a ello, resultó un rotundo fracaso, ya que funcionó poco y mal casi desde el principio ${ }^{53}$.

El acueducto de Buzeta quedó plasmado en un espléndido dibujo, que cobra gran relevancia al no conservarse la obra ${ }^{54}$. Está encabezado en su ángulo superior izquierdo por el escudo de España, quizá como el que tuvo la fuente de la plaza Mayor. Junto a este escudo hay una leyenda que dice:

Plano de la ciudad de Guadalaxara, en los reinos de la Nueva España, cabesera del de la Nueva Galicia y demostración de la real obra del agua con que ha hermoseado y beneficiado la real piedad de su rey y señor don Phelipe V, destinados para su consecución varios ramos de su real hazienda, y con que da quenta el coronel de infantería española marqués del Castillo de Ayssa, de su consejo, governador y capitán general de dicho reino y presidente de la real audiencia del, quien como superintendente de dicha real obra, conduxo el agua de la real caxa en que la dejó el marqués de Altamira, del mismo consejo, oidor de dicha real audiencia con motivo de su assenso a la de México. Guadalaxara y septiembre 16 de 1741 años.

Destaca de esta leyenda que entienda la obra como decoración urbana, así como el papel protagonista que se otorga al rey Felipe $\mathrm{V}$ y a sus dos grandes valedores, el marqués de Altamira y el marqués del Castillo de Aysa.

No obstante, la leyenda más interesante del dibujo es la que aparece bajo el escudo, en la que se hace una detallada descripción de toda la obra en la ciudad:

Tiene esta cañería, desde el arca a la plaza, 1588 baras de dos caños, 14 suvientes de a 4 y a 5 baras según los terrenos y bara y media de grueso, ban demostradas con esta figura (un cuadrado) ay construidas 24 fuentes comunes y particulares, las primeras con esta figura (dos círculos concéntricos) y las otras con los nombres de los compradores, ay otras fuentes proyeitadas con esta figura (dos círculos concéntricos, el interior de color rojo) desde el arca para el ueste suve la tarxea 7 quartas y dos tersias de ancho devaxo de tierra 1489 baras y para el norte de la misma fábrica sube 370 baras y desde el brazo del ueste corre para el sur 5200 baras de tarxea de media bara en donde ai manantiales i en las partes secas de cañería de dos arcos en profundidad de 12 y de 14 baras con sus registros en las partes que empieza cañería y targea tapadas devaxo de tierra por los daños que se experimentaron y señala por si se ofresiere de que dexo quaderno con todas las prevenciones necesarias para su conservación. Fray Pedro Antonio Buzeta, franciscano.

${ }^{53}$ Sobre la arquitectura de Guadalajara, donde el acueducto de Buzeta no es más que un recuerdo, véanse al menos Mata Torres, 1979 y Guía arquitectónica esencial..., 2007. Sobre el acueducto tras Buzeta remitimos a López Cotilla, 1942 y Jalomo Aguirre, 2011.

${ }^{54}$ AGI, Mapas y planos, México, 138. El dibujo es recogido en Calderón Quijano, 1984: 64-66. 


\section{Figura 4. ACUEDUCTO DE GUADALAJARA}

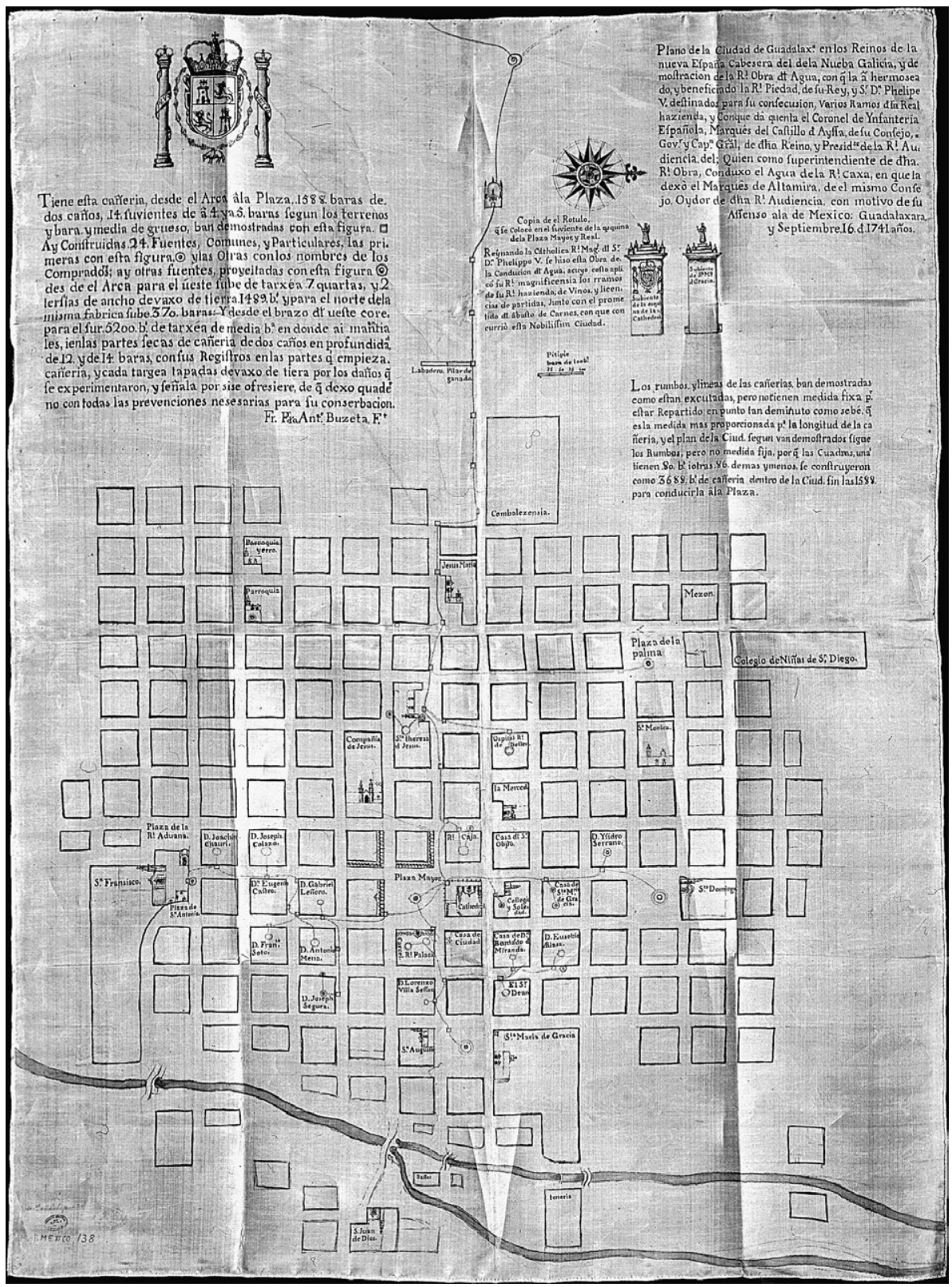

Obra de fray Pedro Antonio de Buzeta, 1741, Archivo General de Indias, Mapas y planos, México, 138. 


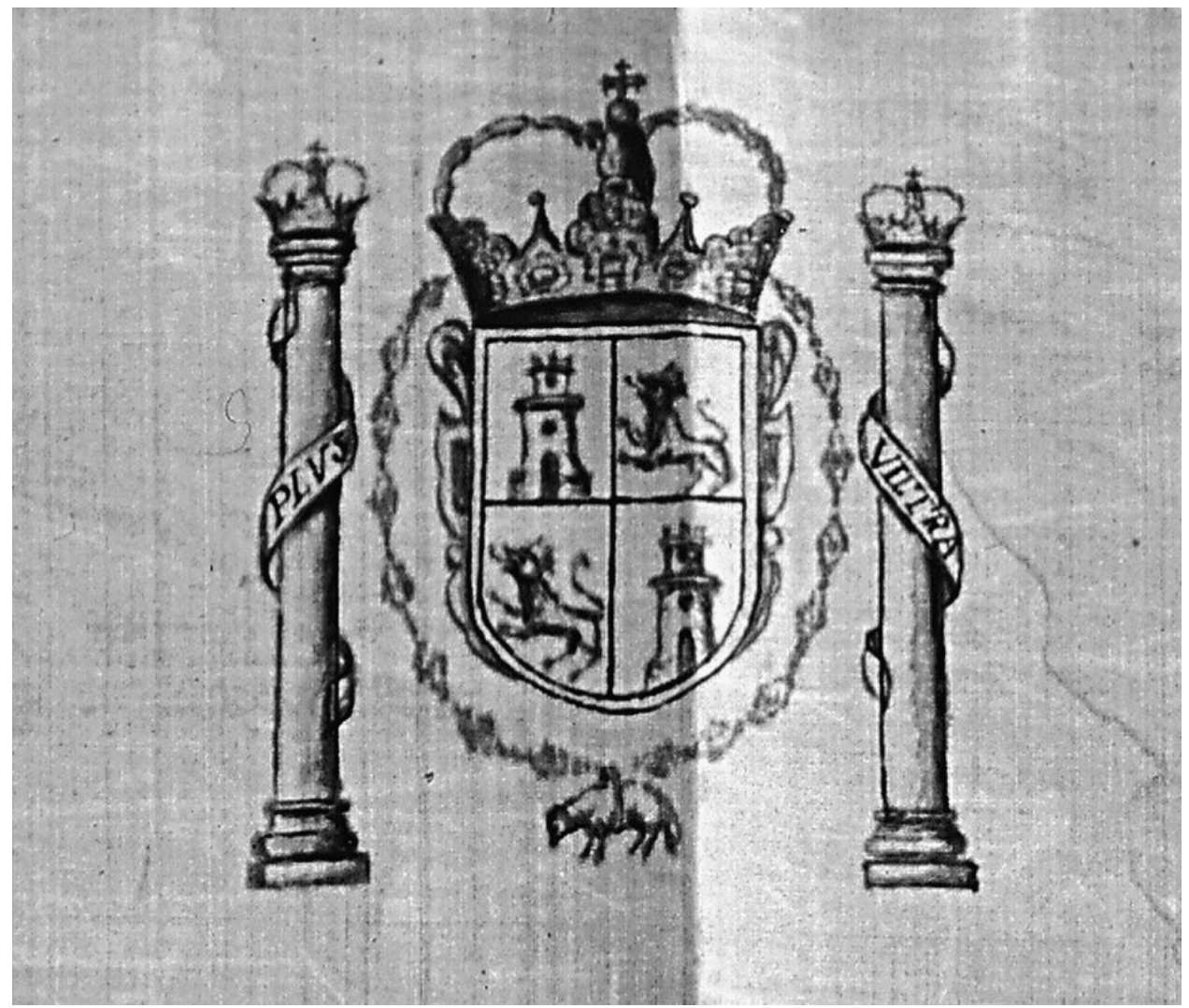

Obra de fray Pedro Antonio de Buzeta, 1741, Archivo General de Indias, Mapas y planos, México, 138. Detalle del escudo de España.

Entre los dos textos anteriores hay un tercero, escrito con letra de tamaño algo menor y que dice:

Copia del rótulo que se colocó en el subiente de la esquina de la plaza mayor y real: Reynando la cathólica real magestad del señor don Phelippo V se hiso esta obra de la condución del agua a cuyo costo aplicó su real magnificensia los rramos de su real hazienda de vinos y licencias de partidas junto con el prometido del abasto de carnes con que concurrió esta nobilísima ciudad.

Podría entenderse así que el abastecimiento de agua a Guadalajara fue un regalo del Felipe $\mathrm{V}$ a la ciudad, e incluso un monumento parlante al pro- 
pio rey, una elocuente manera de mostrar Guadalajara su sumisión a él y su agradecimiento.

Junto a este último texto aparecen dos dibujos de otras tantas fuentes, la primera de las cuales está rematada por una escultura identificable con San Antonio, al que estaba dedicada la obra, y que en su frente tiene un escudo de España, como el que encabeza el plano y bajo él una inscripción que dice «subiente de la esquina de la catedral». Junto a ésta hay otra fuente rematada por una escultura que cabe identificar con San Francisco, en cuyo frente dice «subiente de Santa María de Gracia». Serían las dos fuentes más importantes del conjunto, que pese a su parecido están jerarquizadas, destacando la primera por contar con el escudo patrio.

\section{Figura 6. Detalle de las fuentes del Acueducto de Guadalajara}

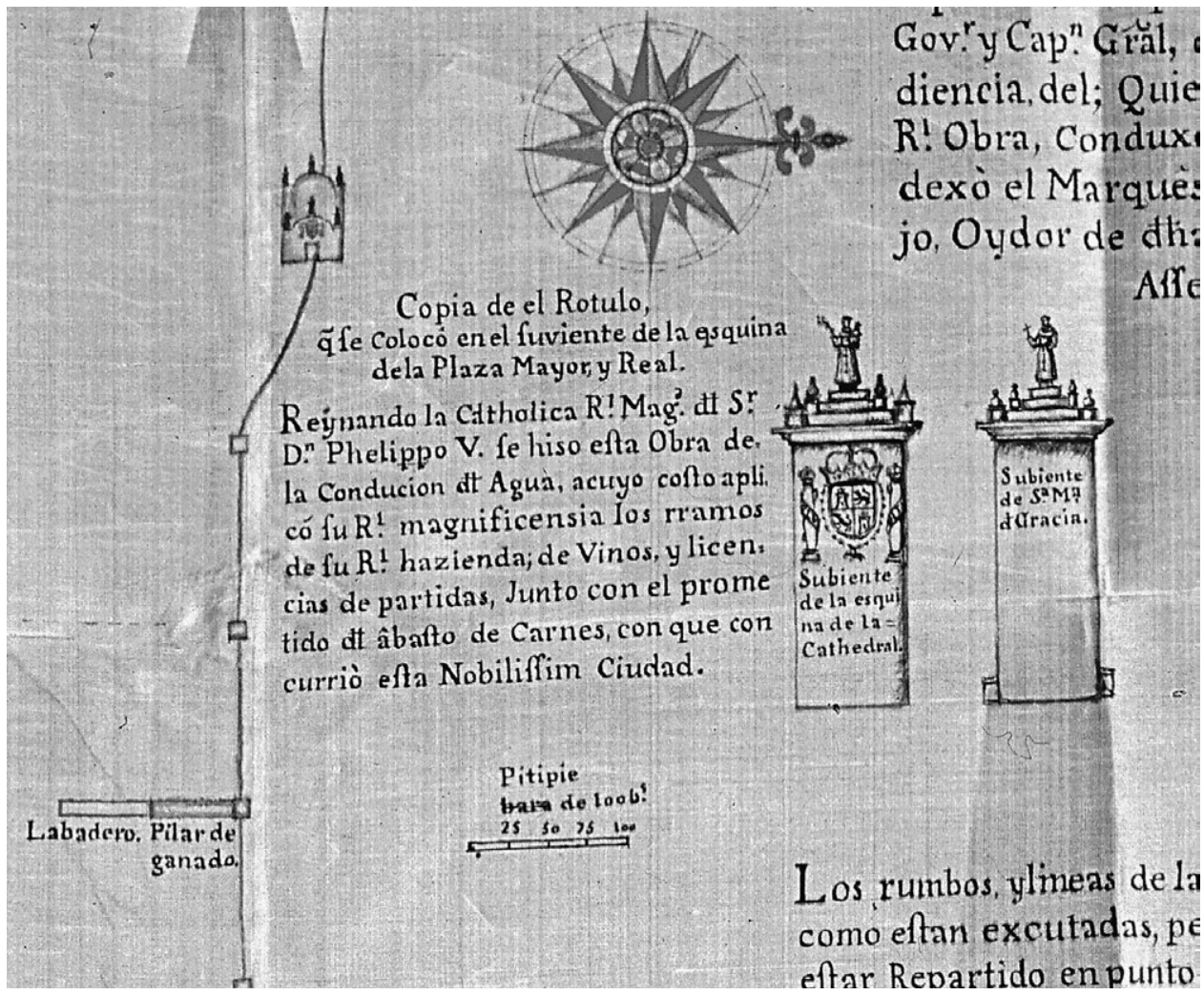

Obra de fray Pedro Antonio de Buzeta, 1741, Archivo General de Indias, Mapas y planos, México, 138. 
Ambos dibujos son los únicos testigos de las fuentes del acueducto, sus elementos más monumentales, junto al arca del agua, ya que el de Guadalajara carecía de las arquerías de otros acueductos novohispanos ${ }^{55}$. En cualquier caso estas fuentes son de una gran sobriedad, apenas unos pilares rematados por las esculturas de sus santos titulares y sólo adornadas con pirámides de tradición herreriana, careciendo del ornamento propio de la arquitectura novohispana de la primera mitad del siglo XVIII.

Un cuarto texto del plano dice:

\begin{abstract}
...los rumbos y líneas de las cañerías ban demostradas como están executadas, pero no tienen medida fixa por estar repartido en punto tan deminuto como sabe que es la medida más proporcionada para la longitud de la cañería y el plan de la ciudad según van demostrados sigue los rumbos pero no medida fija por que las cuadras unas tienen 80 baras i otras 86 de más y menos se construyeron como 3688 baras de cañería dentro de la ciudad sin las 1588 para conducirla a la plaza.
\end{abstract}

Se trata de información técnica de las cañerías que repartían el agua por la ciudad, en un «plan» que abarcaba la mayoría de su superficie. No obstante y a pesar de la importancia de esta información, la leyenda reconoce que era sólo aproximada, de lo que podría desprenderse que este plano, más que una finalidad técnica, aspiraba a mostrar la envergadura de la empresa de forma plástica e inteligible para los funcionarios que tuvieran que verla en el Consejo de Indias, a donde fue enviado.

Otra cuestión interesante es que el plano de 1741 indica las veinticuatro fuentes públicas y privadas levantadas. Las privadas hacen alusión a las mercedes de agua, cuyos beneficiarios aparecen en el plano: Joaquín Chaurri, José Calazo, Eugenio Castro, Gabriel Leñero, Francisco Soto, Antonio Mena, Lorenzo Villaseñor, Bernardo de Miranda y el deán Eusebio Ariasa. También está señalada la casa del obispo, pero parece que no tenía en ese momento agua, al menos no aparece conectada con el resto del sistema de abastecimiento. También nos informa el plano de las fuentes públicas, que estaban en el convento de Santa Teresa, el hospital de Belén, la cárcel Real, la plaza Mayor, la plaza de San Antonio y la plaza de San Agustín. Aún señalaba Buzeta, como vimos, las fuentes que se podrían disponer en un futuro: en la parroquia, en la plaza de la Palma, en Santo Domingo, en casa de José Segura, en la iglesia de la Soledad, en Santa María de Gracia o en casa de Isidro Serrano. Es decir, la obra era susceptible de ser ampliada. Quizá esa fue una de las intenciones de Buzeta al hacer el plano y enviarlo a España, mostrar lo realizado, pero también lo que aún se podría realizar.

${ }^{55}$ Sobre estas arquerías véase Romero de Terreros, 1949. 
Figura 7. ACUEDUCTO DE GUADALAJARA

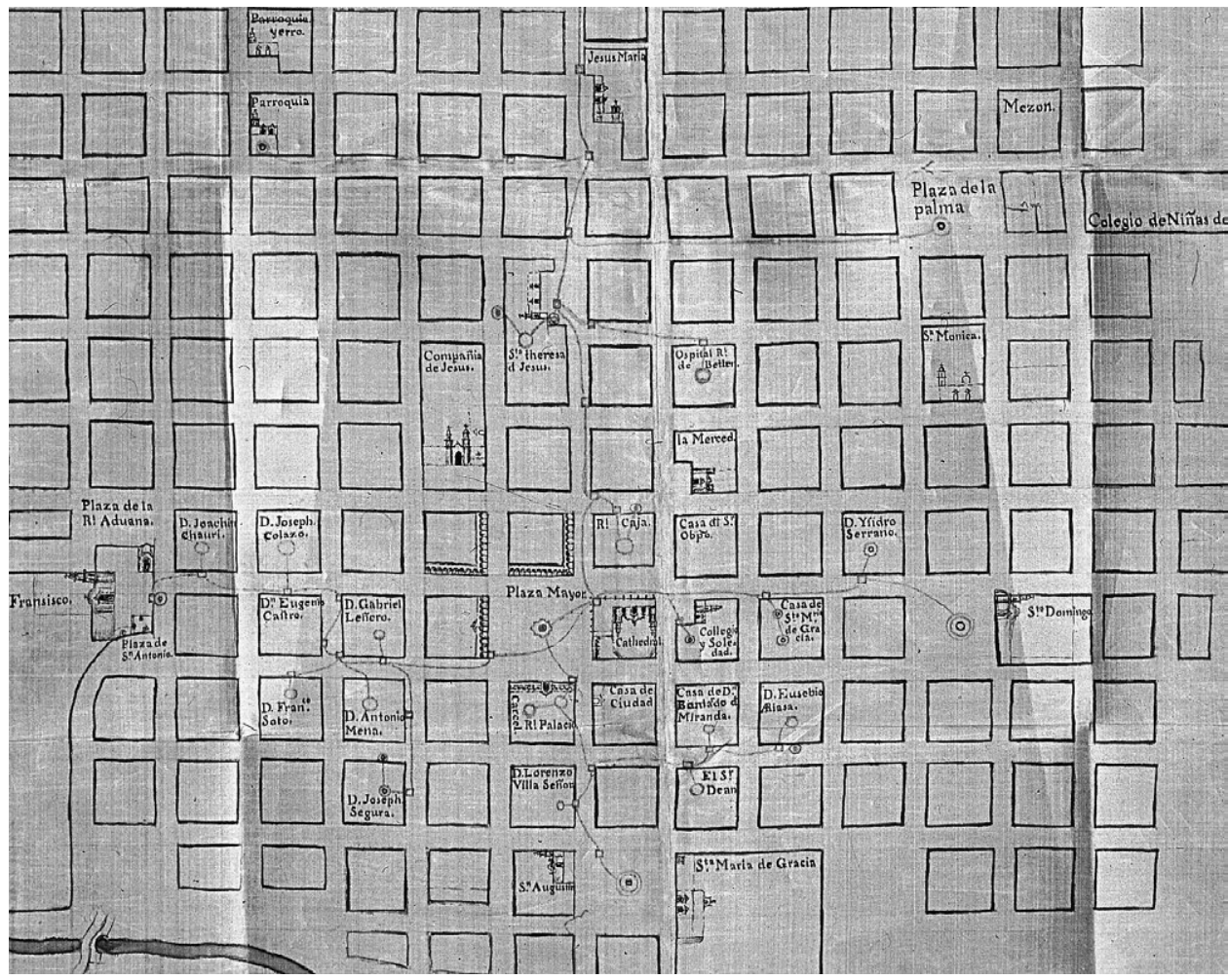

Obra de fray Pedro Antonio de Buzeta, 1741, Archivo General de Indias, Mapas y planos, México, 138. Detalle del centro de la ciudad.

También este plano muestra la disposición de otros elementos del acueducto. Así, en el Oeste aparece la unión de los dos ramales de la conducción de agua y muy próximo el edificio de la caja o arca del agua. Aunque realmente no llegó a configurarse una tipología de las cajas de agua, cabe recordar, por ejemplo, la neoclásica de San Luis Potosí, de planta circular y clara voluntad artística. Estos edificios, por lo general, fueron grandes construcciones de planta rectangular, como la de Guadalajara según el dibujo, que parece indicar que estaba coronada por un escudo de España. A continuación de la caja, en el acceso a la ciudad estaban el lavadero y la pila de ganado. Por otro lado, en el Oeste aparecen unos baños de aguas medicinales y la tenería también aludida en las fuentes. 
El plano de 1741 identifica también los principales edificios de la ciudad, San Francisco al Sur, Santa María de Gracia al Este, la «convalezensia» al Oeste o al Norte el «colegio de niñas de San Diego». Lógicamente, en el centro se agolpaba la edilicia institucional: catedral, palacio real-cárcel, caja real, palacio episcopal, «casa de ciudad» o ayuntamiento. No lejos se encontraban las órdenes religiosas: Compañía, Merced, hospital de Belén o Santo Domingo. No faltan otros templos, como «la parroquia» o «Santa Mónica». También quedan reflejadas las plazas: Mayor; Santo Domingo; San Agustín; la «plaza de la real Aduana» o la «plaza de la Palma». El plano tiene aún ciertos detalles que le dan un carácter costumbrista, como que señale el «mezón», aludido en la documentación o los puentes existentes al Este de la ciudad.

En relación al urbanismo, cabe destacar el sentido mucho más exacto de este plano que del boceto de 1732, a pesar de que ambos son del mismo autor, que en este caso sí lo firmó. Sin duda, el de 1741 supone la culminación del acueducto de Guadalajara. Su finalidad era ser enviado a España, al Consejo de Indias. No es de extrañar que Buzeta se esmerase en él, lo que cabría entender como la certificación de su triunfo frente a los obstáculos salvados. A pesar de ello, no falta algún error, como indica el propio plano acerca de la ubicación de la parroquia, al aparecer su nombre tachado y junto a ello «yerro».

\section{La obra de fray Pedro Antonio de Buzeta en España y Nueva España}

La documentación de la obra de Guadalajara recoge el curriculum de Buzeta, realizado por él mismo. A su actividad novohispana hay que sumar su estela en España, de lo que informa Velázquez-Gaztelu, que conoció al franciscano. Al referirse a él lo llama «nuevo fundador y restaurador del famoso y magnífico templo y casa que hoy disfrutan» los franciscanos en Sanlúcar de Barrameda, al que se habían trasladado por falta de agua en el anterior. En su obra Fundaciones de todas las iglesias, conventos y ermitas de Sanlúcar de Barrameda, fechada en 1758 dice que Buzeta era gallego y «que lo conocimos y tratamos mucho en esta ciudad y en la Nueva España», de la cual regresó a los 78 años, teniendo la satisfacción de morir viendo «su iglesia concluida el día 19 de septiembre de 1748. Siendo su cuerpo el primero que estrenó el suntuoso panteón que bajo del altar mayor hizo construir». Añade que fue «maestro albañil, especialista en las obras de guiar las aguas por cañerías desde cualquier distancia y profundidad en que estuviesen a los sitios donde necesitaban». Así, «sirvió mucho a su religión en las diferentes obras 
de esta clase que hizo en los conventos a donde la obediencia lo enviaba, y este motivo fue el que le trajo la primera vez a Sanlúcar, para la conducción de agua del convento viejo, al nuevo y a la fuente de Santa Clara, trabajando también en las cañerías de agua de las minas de esta ciudad, a la alcuba que subsiste en la puerta de Jerez» ${ }^{56}$.

También apunta Velázquez-Gaztelu la relación del franciscano con América: «deseosos los reverendísimos provinciales de esta religión del adelantamiento de esta nueva fundación dieron permiso a Buceta para que los subsidios de su trabajo exterior se aplicasen a este loable fin y para ello permitieron hacer a la Nueva España tres viajes».

Lo que recaudó, «con su demanda de San Antonio de Padua», y lo que ganó, «con su trabajo personal en las diferentes obras de cañerías y acueductos que hizo en aquellos reinos, pudo en su primer viaje levantar un ángulo del dormitorio para su comunidad, en el segundo echar los cimientos a la nueva iglesia y levantarla hasta las cornisas y en el tercer viaje, en que demoró algunos años, hizo remesas con que se levantó el segundo ángulo del dormitorio».

Al regresar a España aún «hizo cerrar de bóvedas la iglesia y concluir toda su material obra» ${ }^{57}$.

En relación a los viajes de Buzeta a Nueva España, sólo contamos con dos licencias a Indias, una de 1720, por cuatro años, y otra de 1730, por seis. Ambas fundamentadas en pedir limosnas para su convento de Sanlúcar ${ }^{58}$.

No obstante, no fue Buzeta el ejecutor material del templo de Sanlúcar. De él dice Velázquez-Gaztelu que fue su maestro mayor «desde los cimientos hasta el cerramiento de bóvedas Juan Rodríguez Portillo, natural de Morón y vecino de esta ciudad, donde ha fabricado las casas más insignes que hoy tenemos en Sanlúcar y vivió bastante para empezar y concluir San Francisco, que en sus diversas paradas tuvo más de veinte años de duración la obra, valiéndose de sus dos hijos Antonio y Lázaro, tan insignes maestros como su padre».

Sin embargo, aunque todo parece indicar que ellos se encargaron de su construcción y traza, Velázquez-Gaztelu dice que Buzeta intervino en ciertos elementos: «la torre comenzó bien y su primer cuerpo está perfectísimo, pero faltaron los medios para concluirla con otros dos de igual simetría, que vimos en su modelo y se vio obligado el maestro a concluirla semipiramidal, defectuosa, en la forma que la vemos, por obedecer al padre Buzeta».

\footnotetext{
56 Velázquez-Gaztelu, 1995: 158 y 159.

57 Ibidem: 159.

58 AGI, Contratación 5470, $\mathrm{n}^{\circ}$ 3, r. 24 y Contratación 5478, nº 2, r. 24.
} 
Figura 8. IGLESIA DE SAN FRANCISCO

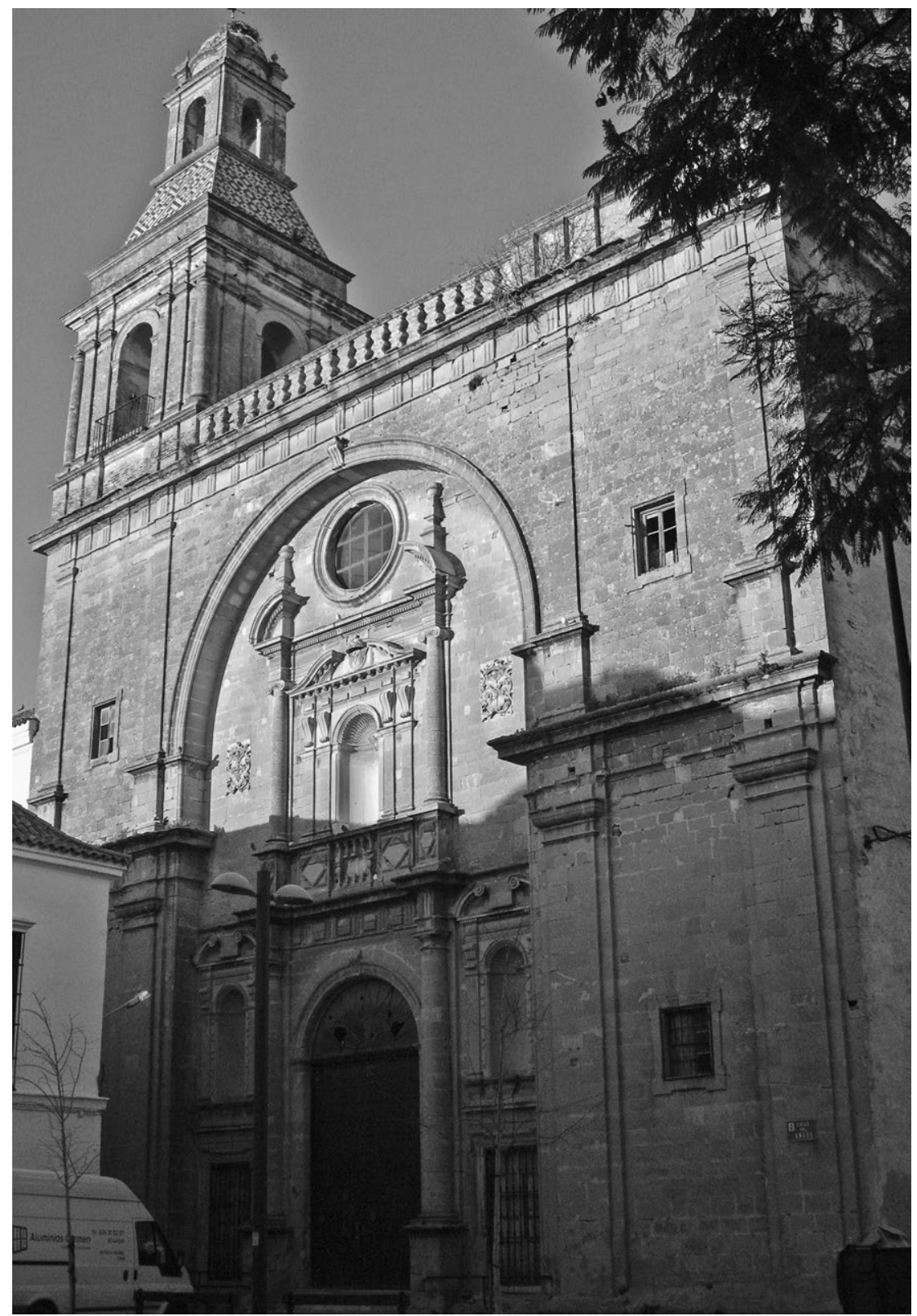

Iglesia de San Francisco, Sanlúcar de Barrameda (Cádiz), Juan Rodríguez Portillo y fray Pedro Antonio de Buzeta, 1700-1752. 
También «su fachada de cantería merece todo aplauso y nos consta que algunos defectos menores que se notan en toda la obra no son del maestro sino de quien la dirigía» ${ }^{59}$.

El propio Buzeta, en relación a la construcción del acueducto de Guadalajara, completa su biografía. Empieza señalando que en 1730 volvió a Nueva España para pedir limosna

...para la fábrica de mi convento y su iglesia en la ciudad de Sanlúcar de Barrameda que yo he planteado y ganado a fuerza de mi industria, sudor, desconsuelo y trabajo en la obra de agua que hize en la ciudad y puerto de la Nueva Veracruz. En ella tuve también mucha batería de murmuraciones porque era obra al símil de esta y aún con mucha menos disposición para la altura en una arena que cada día la muda y amontona en viento en una parte a otra y con otros escollos y dificultades bastantes que en tanto años no se avían podido vencer y yo a Dios gracias lo he ejecutado dexando la obra desde el año 1725 perfecta y acabada sin que aya tenido novedad alguna ${ }^{60}$.

Sobre Veracruz cabe decir que en 1704 el ingeniero militar Luis Bouchar presentó un proyecto para llevar el agua desde el río Xamapa mediante un canal que podría ser navegable y que también serviría para reforzar las fortificaciones de la ciudad, pero nada de ello se hizo ${ }^{61}$.

Lo que el franciscano sí realizó fue llevar el agua del arroyo Tenoyo ${ }^{62}$. En la licencia para volver a Nueva España de 1730 explicaba que «se ocupó dos años y medio de los quatro que se le concedieron con azierto y celo de orden del marqués de Valero, virrey de aquel reyno, en la utilísima obra de conducir a la ciudad de la Veracruz el agua del rio que resultó en especial servicio mío y del bien público» ${ }^{63}$.

Ello lo llevó a cabo «por cañería a una de las plazas de esta ciudad y a la marina», es decir, de forma subterránea, como luego haría en Guadalajara. Buzeta se encontraba en 1722 en Zacatecas y desde ella en carta de 1 de julio señaló que para ir a Veracruz se le habrían de pagar 4000 reales anuales. La ciudad, a pesar de reconocer que no había otro «maestro de más satisfacción en aquel reino», le ofrecía sólo 2500 , que aceptó ${ }^{64}$. La obra la ejecutó en los años 1723 y 1724 .

\footnotetext{
59 Velázquez Gaztelu, 1995: 162. Sobre esta iglesia véase también Cruz Isidoro, 20082009: 173-197.

60 AGI, Guadalajara 420, fols. 246 vto. y 247.

61 Laorden Ramos, 2008, vol. I: 36 y 37.

62 Ibidem: 37 y 38.

63 AGI, Contratación, 5478, n 2, r. 24, fol. 4 vto.

64 AGI, Guadalajara 420, fols. 161-162.
} 
No obstante, su labor en Veracruz fue pronto cuestionada. Se dijo que el agua del Tenoyo causaba enfermedades, de manera que en 1754 el primer conde de Revillagigedo encargó al ingeniero militar Carlos Luján que llevarse desde el rio Xamapa agua a la ciudad. El presupuesto presentado por Luján fue tan alto que no se ejecutó, lo que ocurrió con otros proyectos posteriores, hasta que a fines de dicho siglo se hizo una presa proyectada por el ingeniero Miguel Corral en 1784, en cuya ejecución intervinieron otros ingenieros, como Miguel Constanzó ${ }^{65}$.

También tuvo relación Buzeta con el acueducto del santuario de los Remedios de la ciudad de México, donde para salvar un profundo bajío

...ofreció uno hacer una torre de cincuenta varas de alto y haviendoseme pedido mi parecer lo di por escrito diciendo que cada caso de semejante obra fuese permanente avía de costar de aderezos en diez años más que el principal costo y que tenía por mejor se hicieran arcos sobre arcos, admitiose el dictamen contrario y no sólo sucedió lo que dixe sino también lo que ahora hace más de un año escribió a vuestra merced el señor fiscal de México don Prudencio de Palacios de que después de aver gastado muchos pesos ya no corría el agua en la pila ${ }^{66}$.

El abastecimiento al santuario de los Remedios tuvo su origen en 1616 al donar el virrey marqués de Guadalcázar las aguas necesarias. Para salvar un profundo barranco se construyó un sifón, del que destacan los dos grandes respiraderos que se levantaron en sus extremos en forma de torre, para evitar que bolsas de aire impidieran el paso del agua por la conducción. A la postre, nada de ello funcionó y no fue hasta 1764 cuando, auspiciado por el virrey marqués de Cruillas y con proyecto del ingeniero Ricardo Aylmer, se levantó una arquería de doble piso y 500 metros de longitud, en la que participó Iniesta Bejarano y de la que se conserva sólo el nivel inferior ${ }^{67}$.

También participó Buzeta en la conducción de agua al santuario de Guadalupe, en la ciudad de México. Los orígenes de este acueducto se remontan al virreinato de fray Payo Enríquez de Ribera en el siglo XVII, aunque su construcción no se produjo hasta mediados del XVIII, por lo que suponemos que la participación de nuestro autor se inscribiría en los momentos previos ${ }^{68}$. No sabemos cuál fue su «parecer», el cual no fue atendido, pero es posible que recomendase el abastecimiento subterráneo.

\footnotetext{
${ }^{65}$ Laorden Ramos, 2008, vol. I: 37 y 38.

${ }^{66}$ AGI, Guadalajara 420, fols. 248 y 248 vto.

${ }^{67}$ Romero de Terreros, 1949: 83-91 y Laorden Ramos, 2008, vol. I: 41.

${ }^{68}$ Ruiz Gomar, 1983: 121-145.
} 
Como conclusión, cabe señalar que los acueductos en los que intervino Buzeta, bien como ejecutante, Guadalajara y Veracruz, bien como informador, santuarios de los Remedios y Guadalupe, son algunos de los hitos de la hidráulica novohispana. No obstante, sus informes no fueron atendidos y las obras que ejecutó tuvieron una vida muy efímera. Ello nos obliga a terminar señalando que la actividad de fray Pedro Antonio de Buzeta, a pesar de su excepcional interés, fue a la postre un fracaso.

\section{BIBLIOGRAFÍA}

Ampudia, Ricardo, Estampas de acueductos mexicanos, México, Skira, 1975.

Arregui, Domingo Lázaro de, Descripción de la Nueva Galicia, México, Gobierno de Jalisco, 1980.

Calderón Quijano, José A. (dir.), Cartografía histórica de la Nueva Galicia, Guadalajara, Universidad de Guadalajara, 1984.

Cornejo Franco, José, Testimonios de Guadalajara, México, UNAM, 1993.

Cruz Isidoro, Fernando, "Patrimonio artístico desamortizado del convento de San Francisco 'el Nuevo' de Sanlúcar de Barrameda (1821-1835)", Laboratorio de arte, 21 (Sevilla, 2008-2009): 173-197.

Escamilla Bran, $\mathrm{M}^{\mathrm{a}}$ Teresa, "Arquitectura para el agua en Santiago de los Caballeros. Principios y soluciones hidráulicas aplicadas", Boletín de monumentos históricos, 16 (México, 2009): 123-141.

García Salinero, Fernando, Léxico de alarifes de los siglos de oro, Madrid, Real Academia Española, 1968.

González Tascón, Ignacio, Ingeniería española en ultramar. Siglos XVI-XIX, 2 vols., Madrid, Tabapress, 1992.

Guía arquitectónica esencial. Zona metropolitana de Guadalajara, Guadalajara, Gobierno de Jalisco, 2007.

Icaza Lomelí, Leonardo F., "Arquitectura para el agua durante el virreinato en México", Cuadernos de arquitectura, 2 (México, 1985): 20-33.

Icaza Lomelí, Leonardo F., "Arquitectura hidráulica en la Nueva España", Antiguas obras hidráulicas en América. Actas del seminario, México, 1988, Madrid, Ministerio de obras públicas y transportes, 1988: 221-251.

Icaza Lomelí, Leonardo F., "Glosario de términos hidráulicos", Boletín de monumentos históricos, 16 (México, 2009a): 192-215.

Icaza Lomelí, Leonardo F., "Mudejarías novohispanas del agua", Boletín de monumentos históricos, 16 (México, 2009b): pp. 6-36. 
Iguiniz, Juan, Guadalajara a través de los tiempos. Relatos y descripciones de viajeros y escritores desde el siglo XVI hasta nuestros días, Guadalajara, Banco Refaccionario de Jalisco, 1950

Jalomo Aguirre, Francisco, Gobernar el territorio entre descentralización y metropolización: el Patronato y el SIAPA como formas de gestión (1952-2006) y escenarios prospectivos, Guadalajara, Universidad de Guadalajara, 2011.

Laorden Ramos, Carlos, Obra civil en Ultramar del Real Cuerpo de Ingenieros, Madrid, Ministerio de Defensa, 2008.

López Cotilla, Manuel (atribución), Historia de la introducción de agua en Guadalajara desde su fundación hasta la fecha en la cual se han refundido todas las noticias importantes que ecsisten en la secretaría del Ayuntamiento y otras que se han adquirido en lo particular, Guadalajara, Imprenta del gobierno, 1842 (Guadalajara, Colegio de Jalisco, 2002).

López, Juan, Guadalajara y sus mandatarios de 1532 a 1986, Guadalajara, Gobierno de Jalisco, 1988.

Mata Torres, Ramón (ed.), Iglesias y edificios antiguos de Guadalajara, Guadalajara, Ayuntamiento de Guadalajara, 1979.

Mota Escobar, Alonso de la, Descripción geográfica de los reinos de Nueva Galicia, de Nueva Vizcaya y Nuevo León, Guadalajara, Gobierno de Jalisco, 1993.

Mota Padilla, Matías de la, Historia del reino de Nueva Galicia en la América Septentrional, Guadalajara, Universidad de Guadalajara, 1973.

Ramírez Montes, Guillermina e Iturrate, José, Un ilustre ayalés en México. Juan Antonio de Urrutia y Arana. 1670-1743, Vitoria, Caja de Ahorros Municipal, 1979.

Ramos, Roberto, "Fray Pedro Antonio Buzeta, O.F.M. Introductor del agua potable en Guadalajara", Divulgación histórica, 5 (México, 1942): 218-226.

Reynoso, Salvador, "Desarrollo histórico de la ciudad", Artes en México, $94-95$ (México, 1967): 26.

Romero de Terreros, Manuel, Los acueductos de México en la historia y el arte, México, UNAM, 1949.

Ruiz Gomar, J. Rogelio, "El acueducto de Guadalupe", Estudios acerca del arte novohispano. Homenaje a Elisa Vargas Lugo, México, UNAM, 1983: 121-145.

Terán Trillo, Yolanda, "Hidromensura, arquitectura y producción en Nueva España", Boletín de monumentos históricos, 16 (México, 2009): 37-57.

Velázquez-Gaztelu, Juan P., Fundación de todas las iglesias, conventos y ermitas de Sanlúcar de Barrameda, Sanlúcar de Barrameda, A.S.E.H.A., 1995.

Fecha de recepción: 7 de abril de 2014 .

Fecha de aceptación: 16 de noviembre de 2014. 


\section{Guadalajara aqueduct and Friar Pedro Antonio de Buzeta's work in Spain and New Spain}

Guadalajara aqueduct, built by Friar Pedro Antonio de Buzeta between 1731 and 1741, was one of the most important viceregal works in the Jalisco capital. Its origins date back to the sixteenth century and its consequences lasted into the nineteenth century. Using unpublished documentation from the Archivo General de Indias, we analyse this building venture and the activities of the man behind it, both in Spain and America.

KeY words: aqueduct; Guadalajara; Friar Pedro Antonio de Buzeta; eighteenth century; sources; construction. 